\title{
PhotoAffinity Bits: A photoaffinity-based fragment screening platform for efficient identification of protein ligands
}

Emma. K. Grant ${ }^{1,2}$, David J. Fallon ${ }^{1,2}$, Michael M. Hann ${ }^{1}$, Ken G. M. Fantom ${ }^{1}$, Chad Quinn ${ }^{3}$, Francesca Zappacosta ${ }^{3}$, Roland S. Annan ${ }^{3}$, Chun-wa Chung ${ }^{1}$, Paul Bamborough ${ }^{1}$, David P. Dixon ${ }^{1}$, Peter Stacey ${ }^{1}$, David House ${ }^{1}$, Vipulkumar K. Patel ${ }^{1}$, Nicholas C. O. Tomkinson ${ }^{2}$, Jacob T. Bush ${ }^{1 *}$

1. GlaxoSmithKline, Gunnels Wood Road, Stevenage, Hertfordshire, SG1 2NY, UK.

2. Pure and Applied Chemistry, University of Strathclyde, 295 Cathedral Street, Glasgow, G1 1XL, UK

3. GlaxoSmithKline, South Collegeville Road, Collegeville, PA 19426, U.S

Advances in genomic analyses enable the identification of new proteins that are associated with disease. To validate these targets, tool molecules are required to demonstrate that a ligand can have a disease-modifying effect. Currently, as tools are reported for only a fraction of the proteome, platforms for ligand discovery are essential to leverage insights from genomic analyses. Fragment screening offers an efficient approach to explore chemical space, however, it remains challenging to develop techniques that are both sufficiently high-throughput and sensitive. We present a fragment screening platform, termed PhABits (PhotoAffinity Bits), which utilises a library of photoreactive fragments to covalently capture fragment-protein interactions. Hits can be profiled to determine potency and site of crosslinking, and subsequently developed as reporters in a competitive displacement assay to identify novel hit matter. We envision that the PhABits will be widely applicable to novel protein targets, identifying starting points in the development of therapeutics.

\section{INTRODUCTION}

Advances in human genome sequencing technologies now enable genome-wide association studies (GWAS) across large populations, providing insights into the genetic origins of disease. ${ }^{1}$ The combination of GWAS with functional genomic analyses (e.g. CRISPR-Cas9 screens), allows identification of pathways and targets with therapeutic potential. ${ }^{2}$ Prior to the initiation of drug discovery efforts, validation of these targets is required, often involving the use of chemogenomic tool molecules to build confidence that a ligand can cause a diseasemodifying effect. ${ }^{3-4}$ For a large proportion of the proteome no tool molecules have been reported, therefore, platforms for rapid ligand discovery are required to enable translation of genomic analyses into medicines. ${ }^{5}$

The scientific community has typically relied upon highthroughput screening (HTS) for the identification of tool molecules, which is often slow and resource intensive. ${ }^{6}$ Bindingdriven assays, such as Affinity Selection Mass Spectrometry (ASMS) and DNA Encoded Libraries (DELs) have recently been developed to accelerate ligand discovery through the efficient screening of large libraries $\left(10^{6}-10^{12}\right.$ compounds). $\cdot^{7-16}$ While these approaches are powerful, they employ lead-like libraries $(\mathrm{MW}>300)$ that generate hits that may suffer from sub-optimal ligand efficiency and can prove challenging to optimise. Additionally, the upfront investment in library generation, and sample handling, limits the accessibility of this screening strategy to the broader scientific community. ${ }^{6}$

Fragment-based lead discovery (FBLD) offers a complementary approach. The use of low molecular weight fragments enables effective coverage of chemical space with a smaller number of molecules, to identify weak but highly efficient interactions. ${ }^{17-19}$ Fragment hits can subsequently be optimised into more potent binders with drug-like properties, as has been demonstrated by the discovery of numerous clinical candidates by FBLD (e.g. FDA approved therapeutics: vemurafenib, ${ }^{20}$ venetoclax, ${ }^{21}$ and erdafitinib $\left.{ }^{22}\right) .{ }^{23-25}$ The primary challenge associated with fragment screening is the requirement for highly sensitive screening technologies to detect weak fragment-protein interactions. ${ }^{26}$ Historically, fragment screening has relied upon NMR monitoring techniques and surface plasmon resonance (SPR), but these approaches are often resource intensive. ${ }^{27}$ Furthermore, methods for hit validation and binding site identification (e.g. structural studies) are then required to enable the appropriate triaging and optimisation of fragment hits. Evolution of next generation fragment screening technologies would facilitate more rapid discovery of protein ligands.

The use of electrophilic fragment libraries has emerged within chemical biology as a powerful approach for the identification of fragment-protein interactions. ${ }^{28-30}$ Electrophilic fragments covalently modify the protein, facilitating the use of intact protein liquid chromatography-mass spectrometry (LCMS) for rapid and robust screening of libraries ( $10^{3}$ compounds) to identify binders. ${ }^{28}$ Covalent fragments that target cysteine residues have been identified and successfully optimised to cell-active tool compounds for proteins including e.g. HOIP and KRas. ${ }^{31-32} \mathrm{~A}$ limitation of these libraries is that a cysteine residue must be present in the vicinity of the binding site, and therefore, only a subset of proteins can be targeted. ${ }^{33-34}$ 
Strategies that enable reaction with a wider range of amino acid residues would expand the number of 'ligandable' pockets that can be pursued, and broaden the applicability of the approach.

Photoaffinity labelling has proved useful for the capture of reversible ligand-protein interactions. ${ }^{35-37}$ Upon irradiation with UV light, photoreactive warheads can covalently crosslink to proximal protein residues, providing a broad method for the covalent capture of reversible ligand-protein binding. Cravatt and co-workers recently reported the use of photoreactive fragments for the identification of fragment-protein interactions in live cells. ${ }^{38}$ This proof-of-concept study highlights an opportunity to screen libraries of fragments in cells to build a fragment-protein interaction database across the proteome. However, the current throughput and sensitivity of the MSbased proteomic readout, as well as the large dynamic range of the proteome, limits the broad adoption of this approach. We hypothesised that the use of photoreactive fragment libraries in a biochemical setting would improve the throughput and enable targeted screening against proteins of interest. Such an approach would build upon electrophilic fragments, with the advantage of being applicable to all protein pockets.

Here we report a fragment screening platform, PhABits, where a library of photoreactive fragments are screened in the presence of purified protein. Hits can be detected by intact protein LC-MS enabling identification of known and new chemotypes. Follow-up studies allow determination of binding affinities and the sites of crosslinking. In order to develop fragments into more potent binders, hit PhABits can subsequently be employed as reporter ligands in a MS-based displacement assay. The PhABit platform enables efficient identification of fragment-protein interactions for binding sites that do not contain cysteine residues. Moreover, the approach enabled rapid detection of fragment hits for KRas4B ${ }^{\mathrm{G} 12 \mathrm{D}}$, which is widely considered to be a poorly tractable target. ${ }^{39}$

\section{RESULTS}

\section{Assembling a photoreactive fragment library}

We anticipated that irradiation of a library of photoreactive fragments in the presence of purified protein, would enable photocapture of weak non-covalent fragment-protein binding, which could then be detected by intact mass spectrometry (Figure 1A). The photocapture event occurs as a two-step process: first, non-covalent fragment-protein binding, characterised by a $K_{\mathrm{D}}$, and second, UV-induced photocrosslinking to capture any reversible interactions, characterised by a crosslinking efficiency. Photoreactive intermediates (e.g. carbenes) rapidly crosslink or are quenched, and therefore photocrosslinking represents a snapshot of the status of the reversible binding equilibrium (Figure 1C). This contrasts with electrophilic libraries where the warhead has a longer lifetime and the extent of modification is time-dependent. A small alkyl diazirine photoreactive group was selected as the crosslinking moiety to minimise any perturbation to binding of the fragment warhead. ${ }^{40-}$ ${ }^{41} \mathrm{~A}$ diverse set of 650 amine containing fragments was selected from the GSK amine collection (aromatic ring count $\leq 2$; $\mathrm{H}$-bond donors/acceptors $\leq 4$; heavy atoms $\leq 15$; $\mathrm{MW} \leq 200$ ), using clustering on chemical fingerprints (Figure 1B). A highthroughput synthetic protocol was employed to couple the amine fragments to a carboxylic acid-functionalised diazirine (R1). Reaction mixtures were directly purified by strong cation exchange (SCX) cartridge, followed by deprotection and reverse phase chromatography where required. This workflow enabled the rapid generation of a library of $556 \mathrm{PhABits}$ (Figure 1B). Analysis of the library's properties confirmed that the fragments covered a chemical space comparable to other commercially available libraries (Supplementary Figure 1). ${ }^{28}$

\section{Photoreactive fragment screening}

The PhABit library was screened against a diverse panel of six proteins: myoglobin, lysozyme, carbonic anhydrase, BRD4$B D 1, B C L 6$ and KRas4B ${ }^{G 12 D}$. The library was incubated with recombinant protein $\left(1 \mu \mathrm{M}, 4{ }^{\circ} \mathrm{C}, 15 \mathrm{~min}, 200 \mu \mathrm{M}\right.$ PhABit) before irradiation with UV light (302 nm, $10 \mathrm{~min}$ ), and direct analysis by intact protein LC-MS (Figure $1 \mathrm{C}$ ). The resulting mass spectra were analysed to identify PhABits that had covalently modified the protein, leading to an additional peak at a mass of [protein+PhABit- $\mathrm{N}_{2}$ ]. A range of crosslinking yields (0-53\%) were observed and hits were classed as strong ( $>5 \%$ crosslinking) or moderate (1.5-5\% crosslinking). In general, the crosslinking yields for hits were low, which could have resulted from either low site occupancy or poor crosslinking due to orientation of the diazirine / quenching of the carbene. Consequently, crosslinking yield was not used as a measure of binding affinity and all hits were followed up. A small number of PhABits ( 1\%) showed multiple crosslinking events, suggesting that the PhABit was bound to a number of different sites on the protein, or potentially formed a long-lived reactive species enabling multiple modifications to take place via diffusion-based crosslinking. This behaviour was indicative of non-selective binding and therefore not considered hits (Figure 1D).

Analysis of the screens generated variable hit rates across the proteins with lysozyme yielding the highest number of crosslinking PhABits (47\%), in contrast to myoglobin with very few binders (<3\%) (Figure 1E). A number of warheads previously reported to bind to the proteins were identified as hits, including two dimethyl isoxazole fragments for BRD4-BD1 (see inhibitor iBET-151 ${ }^{42}$ ), and a series of sulfonamides for carbonic anhydrase (see dorzolamide, ${ }^{43}$ methazolamide ${ }^{44}$ and acetazolamide ${ }^{45}$ ). These hits provided early validation that the PhABit screen could identify true fragment binders.

\section{Promiscuity and non-specific crosslinking}

A key concern in fragment screening is deconvolution of specific versus non-specific interactions. In traditional fragment screening, the latter is usually associated with high lipophilicity or low solubility of the fragment. Electrophilic fragment screens can yield non-selective hits due to high reactivity of the electrophilic warhead, leading to labelling of surface-exposed cysteine residues. ${ }^{28}$ An analogous consideration for photoaffinity labelling is that the reactive intermediate formed upon irradiation should be appropriately short-lived to avoid diffusion-based crosslinking that is not driven by binding affinity. The majority of the PhABits did not crosslink to the proteins screened, indicating that the reactive intermediate was rapidly 
a

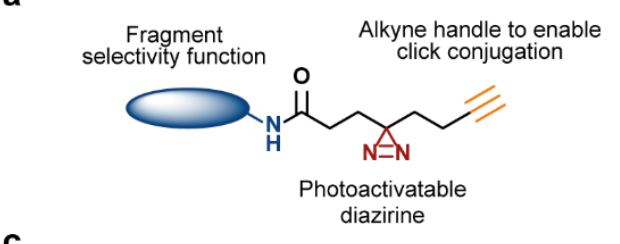

C
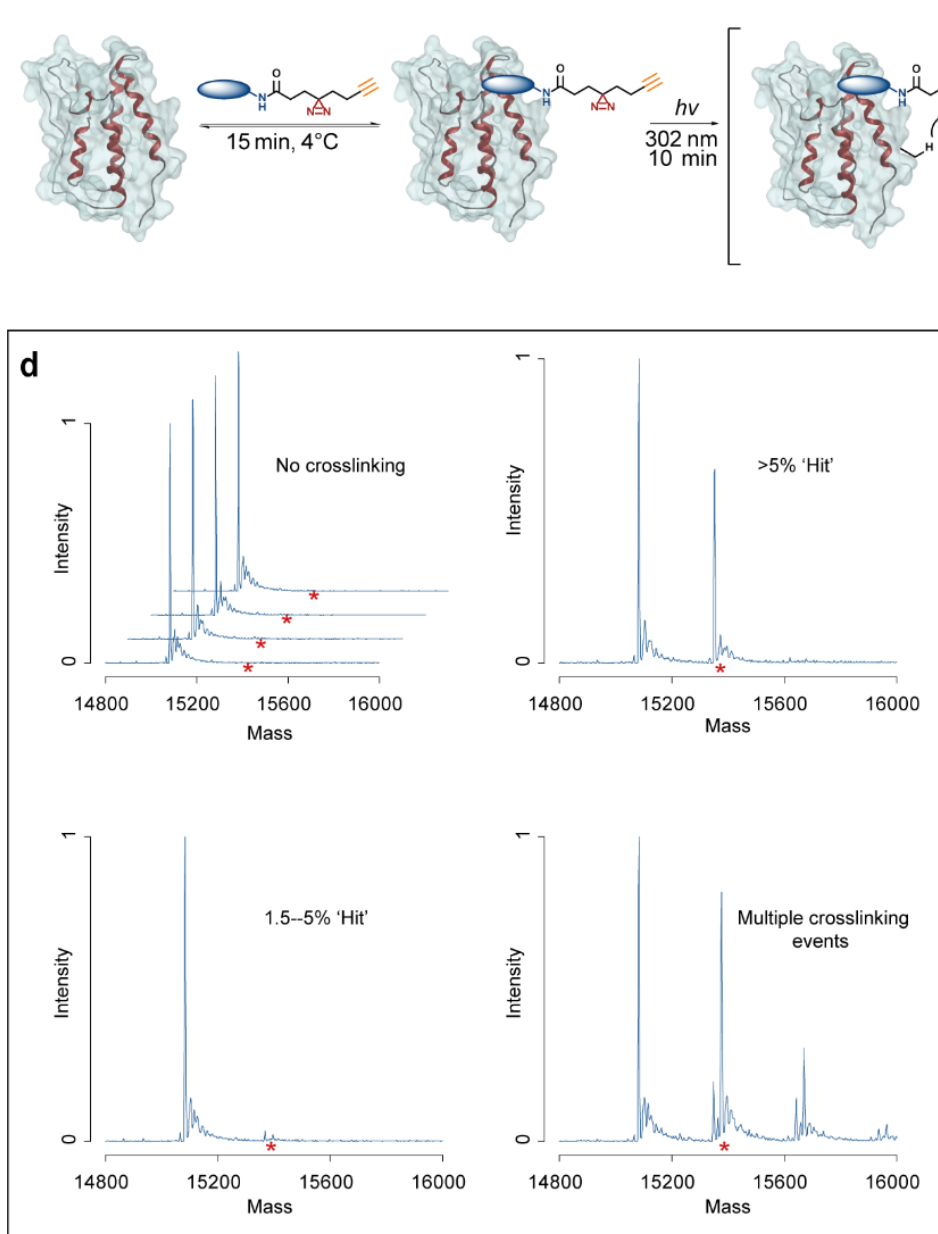

b
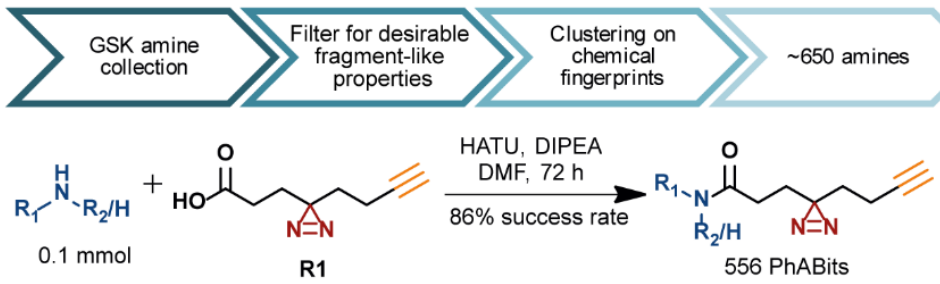

R1
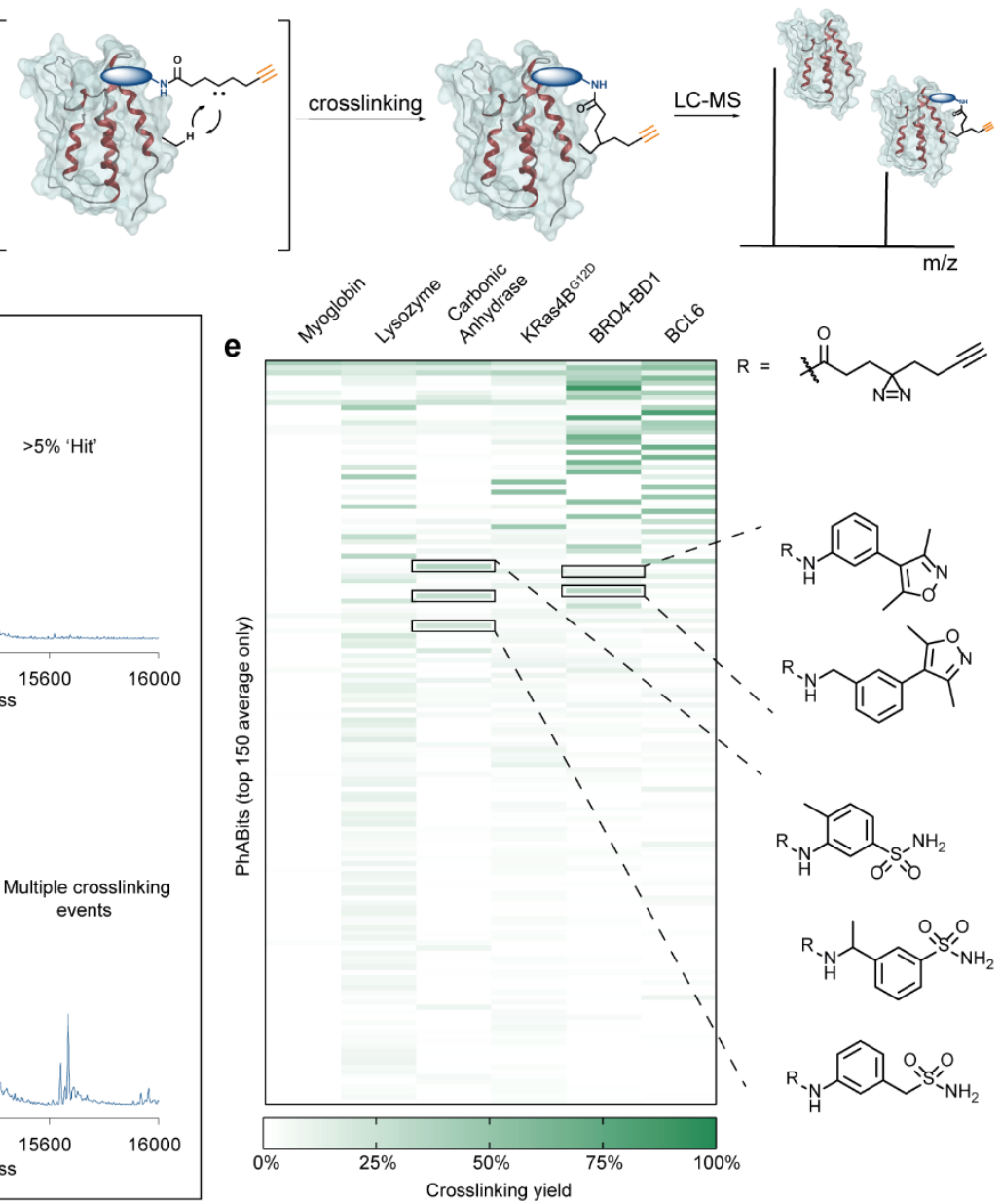

Figure 1: Photoreactive fragment screening. A: General structure of the PhABit compounds, highlighting the three key functionalities. B: Selection of the amines for the PhABit library and subsequent one-step synthetic protocol, giving access to 556 PhABits. C: Schematic of workflow used to screen the PhABit platform against recombinant proteins of interest. Proteins $(1 \mu \mathrm{M})$ are incubated $\left(4{ }^{\circ} \mathrm{C}, 15 \mathrm{~min}\right)$ with PhABit $(200 \mu \mathrm{M})$ before UV irradiation $(302 \mathrm{~nm}, 10 \mathrm{~min})$ and analysis by intact LC-MS. D: Examples of spectra obtained during analysis of the PhABit screen of BRD4-BD1, $\left({ }^{*}\right)$ indicates the expected mass of BRD4-BD1 and crosslinked PhABit. E: Heat map of the PhABit screen against recombinant proteins: myoglobin, lysozyme, carbonic anhydrase, KRas4BG12D, BRD4-BD1 and BCL6. Known binding motifs to both BRD4-BD1 and carbonic anhydrase that were identified in the screens are highlighted.

quenched. However, ten PhABits were found to crosslink to all proteins screened and 58 crosslinked to at least four proteins. These could represent privileged scaffolds that are accommodated by many protein pockets, or be due to non-specific crosslinking either through lipophilic interactions with the protein or formation of long-lived reactive species.

To further investigate the specificity of the 89 PhABits that crosslinked to BRD4-BD1, the screen was repeated in the presence of the BET inhibitor JQ1, which binds within the acetyl lysine pocket. ${ }^{46} \mathrm{JQ1}(10 \mu \mathrm{M})$ was incubated with hit PhABits (200 $\mu \mathrm{M})$ and BRD4-BD1 (1 $\mu \mathrm{M})$ before irradiation and analysis by LC-MS (Figure $2 \mathrm{~A}$ ). For $68 \mathrm{PhABits,}>50 \%$ displacement was observed, indicating that these fragments bind selectively to the acetyl lysine binding pocket. Of the remaining 21 fragments that were not displaced, 19 crosslinked to at least three of the other tested proteins, suggesting non-specific crosslinking. Physicochemical analysis of these fragments did not highlight any properties that would typically cause non-specific binding, e.g. high lipophilicity or low solubility (Supplementary Figure 2). Therefore, it may be that these PhABits form a long-lived intermediate, leading to diffusion-induced crosslinking. In all subsequent screening analyses these PhABits were omitted.

\section{Confirmation and characterisation of BRD4 PhABit hits}

BRD4-BD1 was selected for in-depth analysis of the screening results and follow-up studies on the hits. BRD4 is a member 

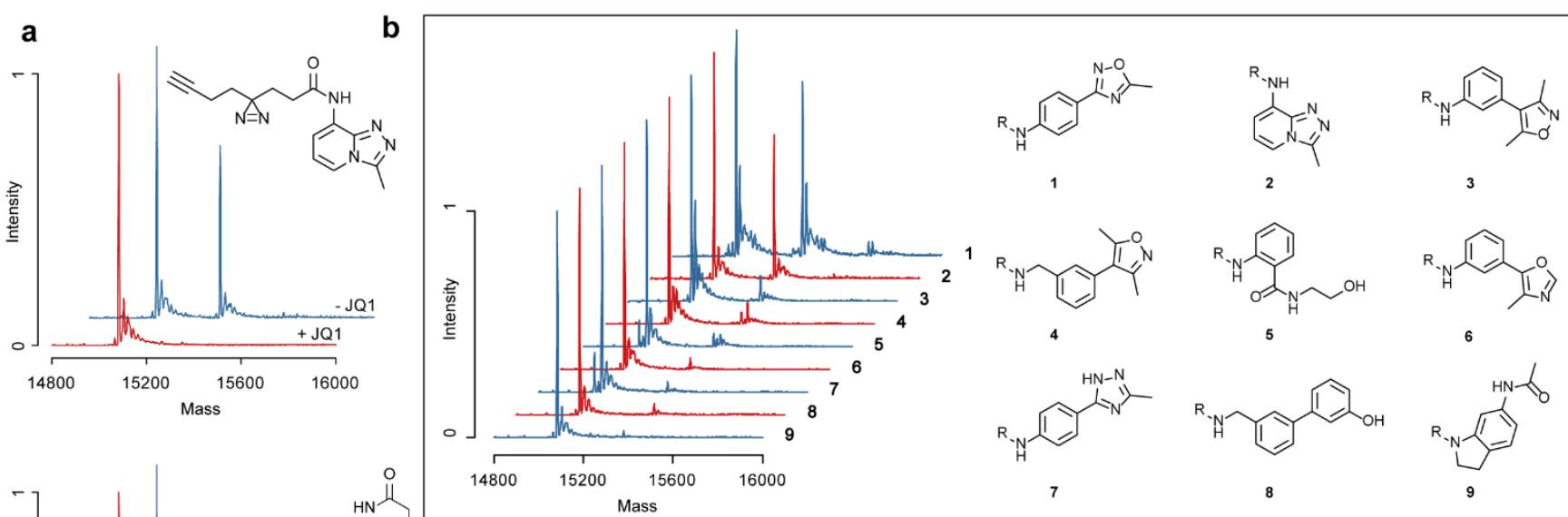

6
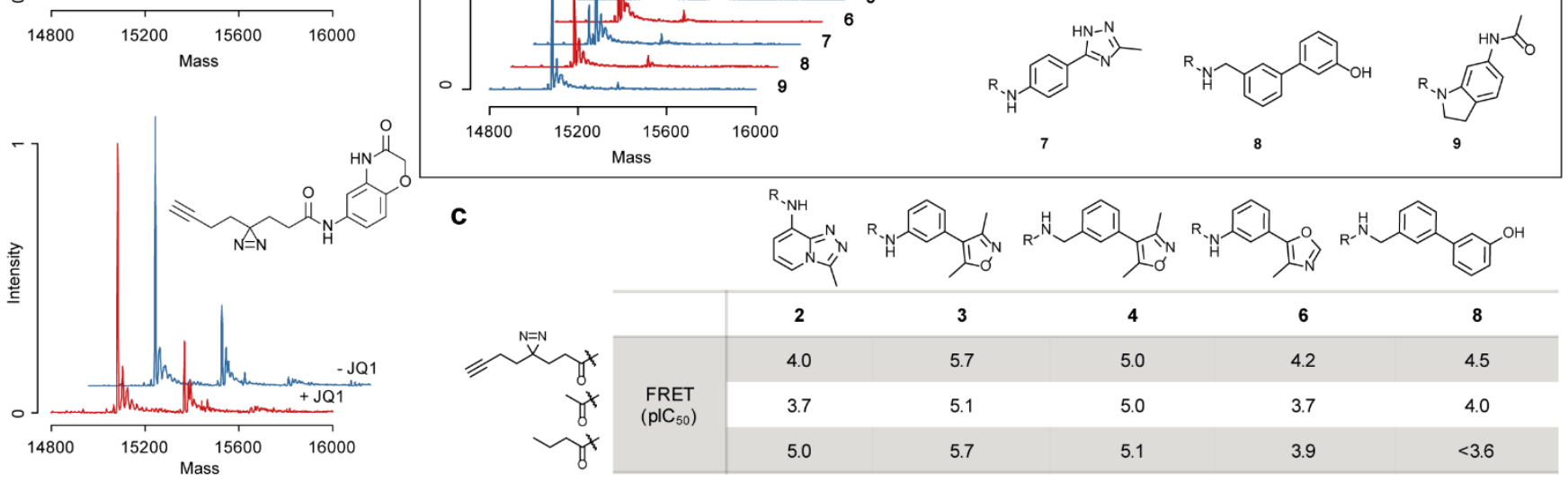

Figure 2: Confirmation and characterisation of BRD4 PhABit hits. A: Intact MS spectra of single shot displacement of two PhABits showing without JQ1 (blue) and pre-incubation with JQ1 (10 $\mu \mathrm{M})$ (red). B: Intact MS spectra and structures of hit PhABits for BRD4-BD1. C: TR-FRET data for selected PhABits and acetyl- and butanoyl-amide analogues.

of the bromodomain and extra-terminal domain (BET) family of proteins, ${ }^{47}$ which are involved in epigenetic regulation and are potential therapeutic targets for the treatment of disease, including cancer and inflammation. ${ }^{48-49}$ The BRD4-BD1 PhABit screen afforded 68 hits (12\%) that were displaced by JQ1, which gave strong (13), and moderate (55) crosslinking. Hits included the aforementioned dimethyl isoxazoles $\mathbf{3}$ and $\mathbf{4}$, other 5-membered heterocycles (e.g. 6 and 7), acetyl lysine mimetics (1 and $\mathbf{9}$ ) and less typical structures (5 and $\mathbf{8}$ ), which could represent novel binding motifs for the acetyl lysine pocket (Figure 2B). Orthogonal confirmation of non-covalent binding to the acetyl lysine binding site was performed using a BRD4-BD1 TR-FRET competition assay. Six of the nine hits (24, 6 and 8-9) were found to inhibit bromodomain-substrate binding with weak to moderate affinity $\left(\mathrm{pIC}_{50}\right.$ values $4.0-5.7$, Figure 2C).

In order to identify hit fragments in the development of therapeutics, the contribution of the photoreactive warhead to binding affinity was investigated. A primary goal of the PhABit platform was to identify hits that can subsequently be developed without the photoaffinity label. A key consideration, therefore, was the contribution of the photoreactive warhead to the binding affinity. Analogues of hit PhABits were synthesised with acetyl- and butanoyl-amides in place of the photoreactive group to explore the impact this had on potency (10-19, Supplementary Figure 3). A decrease of less than 0.6 log units in the TR-FRET assay was observed upon truncating to the acetylamide analogues, and potency was typically recovered in the butanoylamide analogues (Figure 2C). The retention of potency upon removal of the photoreactive moiety confirmed binding was driven by reversible fragment-protein interactions.
The PhABit screen proved straightforward to implement, allowing expedient screening via LC-MS, to identify fragmentprotein interactions. The PhABits were directly applied to a panel of proteins without the requirement for assay optimisation, which is a distinct advantage over many other fragment screening strategies. Further, none of the proteins screened here contain an exposed cysteine, thus highlighting the advantage of photoreactive fragments over cysteine-reactive approaches, by now enabling the identification of binders for any ligandable protein pocket.

\section{FOLLOW-UP STUDIES}

Determination of potency of hit PhABits

We anticipated that a key feature of the PhABit platform would be the opportunity to perform follow-up studies to further characterise the hits and enable appropriate triaging. First, concentration-response studies were performed to measure PhABit binding affinity. Hit PhABits were incubated at a range of concentrations with BRD4-BD1 $(1 \mu \mathrm{M})$ before irradiation and analysis by LC-MS. In all cases, a concentration-dependent reduction in the crosslinking yield was observed (Figure $3 \mathrm{~A}$ ). The resulting curves could be fit to calculate $p K_{\mathrm{D}}$ values, and enabled deconvolution of the crosslinking event; the gradient of the curve is determined by the non-covalent $K_{\mathrm{D}}$ of the fragment, while the plateau represents the maximum crosslinking efficiency of the PhABit (Figure 3B). Importantly, this maximum is independent of the potency of the fragment, and only measures crosslinking efficiency versus other carbene quenching processes. Thus, concentration-response studies enabled differentiation of weak binders with high crosslinking 
efficiency (e.g. 1) and potent binders with poor crosslinking efficiency (e.g. 3). To validate the PhABit-generated $\mathrm{p} K_{\mathrm{D}}$ values, the fragments were also screened by SPR $\left(p K_{D}\right)$ and TR-FRET $\left(\mathrm{pIC}_{50}\right.$ ) assay, which showed good correlation (SPR R ${ }^{2}=0.82$ and TR-FRET $R^{2}=0.90$, Figure $3 C$ ). The concentration-response study thus offers an expedient method for determining the potency of hit PhABits.

\section{Determination of site of binding / crosslinking}

A second feature of covalent crosslinking is that it enables determination of the site of binding without recourse to crystallography. The site of binding can be determined either by competition, where suitable ligands with known binding location are available (e.g. JQ1 as demonstrated above), or by elucidation of the site of crosslinking by LC-MS/MS analysis. This latter approach would be particularly powerful for proteins without known binders or crystallography. PhABit 2 was selected to explore this technique with BRD4-BD1. Crosslinked samples were digested using trypsin/LysC and the resulting peptides analysed by LC-MS/MS. The peptide ${ }_{101}$ PGD*DIVLMAEALEK $_{114}$ was identified as carrying a modification on D103, which was not observed in the non-irradiated control sample (Figure 3D). This residue is at the edge of the acetyl lysine binding site, and ideally situated for crosslinking.
The site of crosslinking was also determined for 3, 4 and 6, which were found to crosslink to a neighbouring aspartic acid residue, D104, suggesting a different orientation of the diazirine, but consistent with binding to the same pocket (Supplementary Figure 4). The binding of PhABit 2 was further investigated by elucidation of a co-crystal structure of $\mathbf{2}$ with BRD4BD1 (without UV irradiation). The structure showed the PhABit warhead binding in the acetyl lysine pocket, forming a hydrogen bond to asparginine N140, with the diazirine group oriented out of the pocket and directly adjacent to residue D103, consistent with the observed crosslinking to this residue (Figure 3E).

Follow-up studies enabled characterisation of potency and binding sites of hit PhABits. The direct measurement of PhABit $K_{\mathrm{D}}$ values that matched those obtained in orthogonal assays is significant, as it enables hits to be prioritised without the development of secondary screens. Further, LC-MS/MS analysis enabled identification of the residue of crosslinking, from which the site of binding could be inferred. These follow-up studies will be particularly impactful in the case of emerging proteins where assays and crystallography are not available, allowing characterisation and progression of hits on the PhABit platform alone.
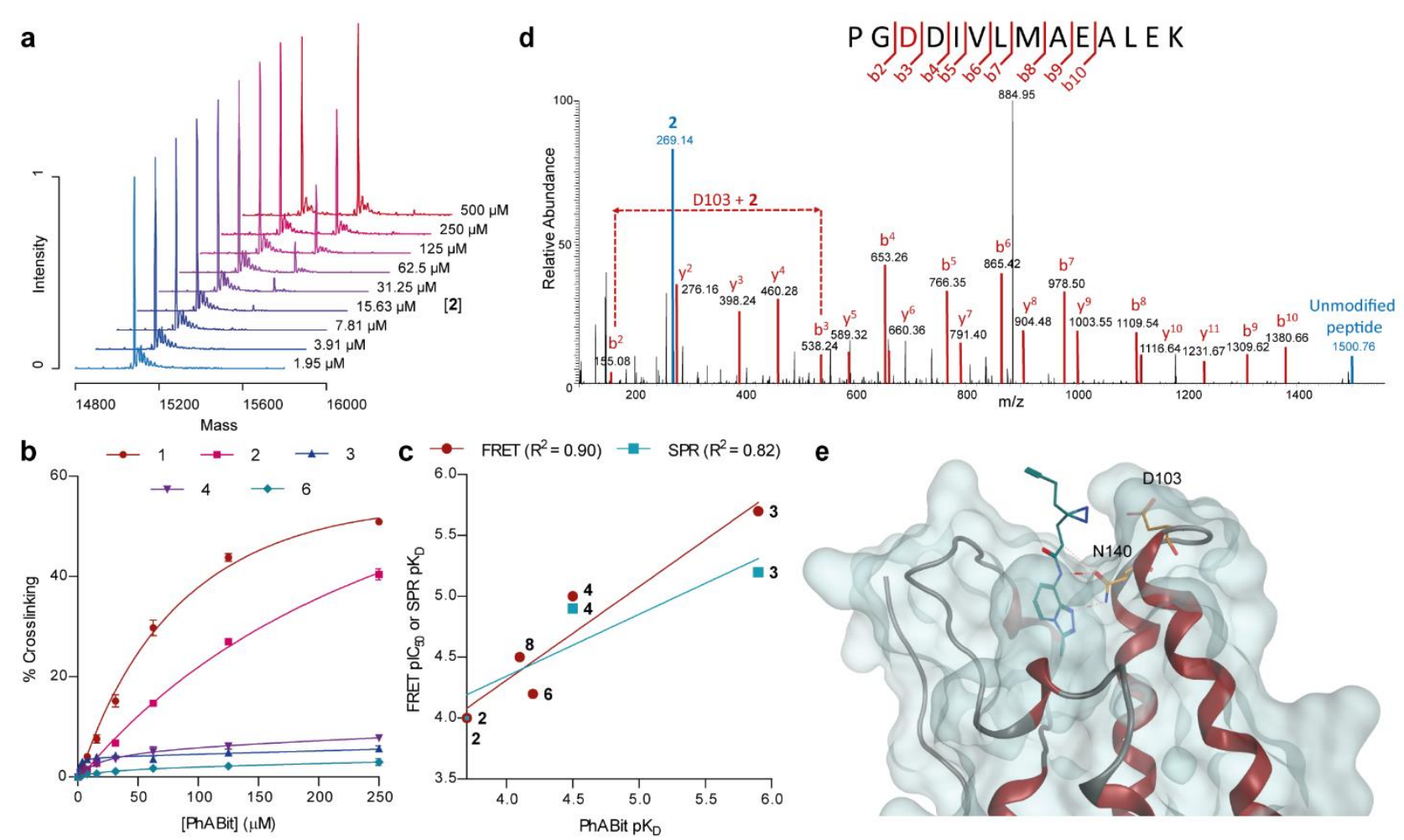

Figure 3: Follow-up studies for hit validation. A: Overlay of the intact MS spectra of $\mathbf{2}$ in a concentration-response manner, crosslinked to BRD4-BD1 following irradiation (302 nm, $10 \mathrm{~min}$ ). B: Plots of the crosslinking yields of hit PhABits treated in concentration-response to BRD4-BD1, error bars represent SEM across three replicates. This data can be used to generate $p K_{D}$ values for each PhABit. C: Comparison of potencies of five hit PhABits generated by concentration-response ( $p K_{D}$ values used) $(n=3) v s$ TR-FRET and SPR assays ( $n=3$ ). The lines of best fit are plotted (SPR $R^{2}=0.82$ and TR-FRET $R^{2}=0.90$ ). D: Following incubation of 2 with BRD4-BD1 and irradiation at $302 \mathrm{~nm}$ for $5 \mathrm{mins}$, the sample was reduced, treated with iodoacetamide and digested using trypsin and LysC. Analysis by LC-MS/MS (mass of [2- $\mathrm{N}_{2}$ ] on any residue as a variable modification) identified peptide ${ }_{101}$ PGD*DIVLMAEALEK $_{114}$ crosslinked to 2, indicating D103 as the site of crosslinking. E: Co-crystal structure of $\mathbf{2}$ bound to BRD4-BD1 pre-irradiation, showing the proximity of the diazirine to the aspartic acid residue which is identified as the site of crosslinking. 
Development of a fragment-based PROTAC for BRD4

It was anticipated that the PhABit platform could be an expedient approach to identify warheads for the development of bifunctional molecules, such as PROteolysis TArgeting Chimeras (PROTACS). PROTACs have recently emerged as a therapeutic strategy, inducing protein degradation by hijacking components of the ubiquitin-proteasome system. ${ }^{50}$ Three PROTACs (P1-P3), derived from PhABits 3, 4 and 8, were synthesised containing a PEG linker conjugated to a VHL-ligase binder (Figure $4 \mathrm{~A}$; for synthesis see Supplementary Figure 5). ${ }^{50}$ Degradation of BRD4 was subsequently measured in HEK293 cells using a HiBiT assay protocol. ${ }^{51-52}$ The higher affinity PROTACs P1 $\left(\mathrm{pIC}_{50}=5.5\right)$ and $\mathbf{P 2}\left(\mathrm{plC}_{50}=5.9\right)$ induced degradation above $1 \mu \mathrm{M}$ (Figure 4B), while PROTAC P3 ( $\left.\mathrm{plC}_{50}=4.7\right)$, did not degrade BRD4 up to $10 \mu \mathrm{M}$, suggesting insufficient fragment affinity. Analysis of the cellular ATP levels indicated that the PROTAC ligands did not inhibit cell growth. Additionally, pre-treatment of the cells with epoxomicin (proteasome inhibitor) reduced degradation of BRD4, supporting degradation via the proteasome (Supplementary Figure 6). The experiment thus highlights that more potent PhABits could be directly employed for the development of PROTACs, to degrade proteins by recruiting components of the ubiquitin-proteasome system. Since the PhABit platform identifies binders and not necessarily inhibitors, coupling this screening methodology with the generation of PROTACs could be an attractive strategy to enable degradation of proteins where inhibition proves challenging (e.g. protein-protein interactions (PPIs) and transcription factors).
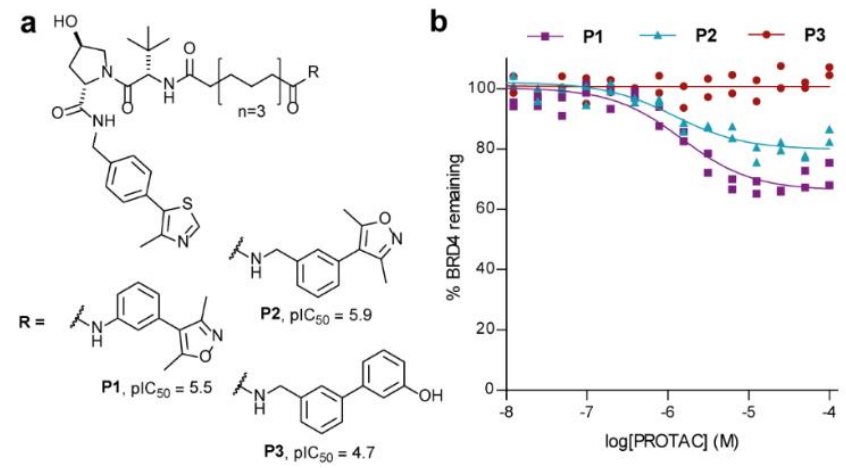

Figure 4: Development of a fragment-based PROTAC for BRD4. A: Structures of the VHL-BRD4 PhABit-derived PROTACs P1-P3, and corresponding TR-FRET-derived $\mathrm{pIC}_{50}$ values. B: Degradation curves of P1-P3 as measured in the HiBiT assay. $\mathbf{P 1}$ and $\mathbf{P 2}$ show a maximum degradation of $28 \%$ and $16 \%$ respectively $(n=2)$.

\section{PHOTOAFFINITY SCREENING TECHNOLOGY}

In the validation of protein targets of interest, rapid development of fragment hits towards more potent tool molecules is essential. It was anticipated that hits from the PhABit screen could be used as reporters for site-specific displacement assays to enable immediate screening. Compounds that compete with the reporter PhABit would induce a concentration-dependent reduction in crosslinking, enabling calculation of $\mathrm{plC}_{50}$ values (Figure 5A). ${ }^{53} \mathrm{~A}$ proof-of-concept study was performed using PhABit 2 to develop a binding assay for BRD4-BD1 (Figure $5 B$ ). A library of $\sim 1000$ compounds was selected based on a similarity search (Tanimoto, $>0.7, \mathrm{MW}<400 \mathrm{Da}$ ) from the hit PhABits identified previously (1-9). The compounds were incubated with PhABit 2 and BRD4-BD1 before irradiation and analysis by LC-MS to determine crosslinking yield. A range of crosslinking inhibition was observed from $1-100 \%$, with $>50 \%$ observed for 208 compounds ( $21 \%$ of the total screen) (Figure $5 \mathrm{C})$. The majority of these hits were derived from dimethylisoxazole PhABits 3 and $\mathbf{4}$, consistent with the presence of this motif in a number of BET targeting series in the GSK compound collection. The remaining 40 hit compounds (20-59) were derived from PhABits $\mathbf{2}, \mathbf{7}, \mathbf{8}$ and $\mathbf{9}$ and grouped into four chemical series (Figure 5D). Compounds $\mathbf{2 2}$ and $\mathbf{2 8}$ are structurally related to the pan-bromodomain binder bromosporin and had previously been identified as binding to BRD4-BD1. Compound 58 mimics the acetylated native ligand and relates to other reported acetyl lysine mimetics, while compound $\mathbf{4 0}$ does not resemble known BRD4 binders.

Determination of compound potency using the PhABit displacement assay could be achieved using concentration-response studies. However, advancement from single concentration screening to concentration-response measurements $\left(\mathrm{pIC}_{50}\right)$ was limited by the throughput of LC-MS analysis (7.7 min per sample). The protocol was therefore transferred to RapidFire $^{\mathrm{TM}} \mathrm{MS}$, which uses a desalting cartridge rather than liquid chromatography, enabling analysis at a rate of just 12 seconds per sample. This acceleration in throughput significantly improved the scope of the screening approach.

The 40 selected compounds from the single concentration screen were followed-up in concentration-response mode $(100-1.56 \mu \mathrm{M})$ with analysis by RapidFire ${ }^{\mathrm{TM}} \mathrm{MS}$. The crosslinking yield was found to decrease with increasing concentration of elaborated compounds, consistent with competitive displacement (Figure $5 \mathrm{E}$ ). The data showed good reproducibility across three replicates and the $\mathrm{pIC}_{50}$ values generated were measured across a range of 4-6 (Figure 5F). Values were corrected using the Cheng-Prusoff equation to obtain $\mathrm{p} K_{\mathrm{i}}$ values, based on the $\mathrm{p} K_{\mathrm{D}}$ value of 2 measured previously $\left(\mathrm{p} K_{\mathrm{D}}=3.7\right.$, Figure $3 \mathrm{~B} / \mathrm{C}$ ). To validate the resulting binding affinities, the 40 compounds were also screened in the TR-FRET assay. The assays showed good correlation $\left(R^{2}=0.72\right)$ confirming that the PhABit-based displacement screen was a reliable screening method (Figure 5G).

The direct employment of hit PhABits as reporters in a photoaffinity displacement assay is a key advantage of the platform, enabling the screening of elaborated compound libraries. The adoption of RapidFire ${ }^{\mathrm{TM}}-\mathrm{MS}$ provided a crucial increase in the throughput of the assay enabling rapid progression toward more potent tool molecules, on a timescale and resource load that competes with traditional assay development.

\section{APPLICATION TO OTHER TARGETS}

To explore the range of applicability of the PhABit platform, we subsequently applied it to KRas, which has been widely reported as a protein with low tractability towards small molecule binders. ${ }^{39}$ KRas oncogenic driver mutations are found in $30 \%$ of cancers. The mutations result in constitutive activation of KRas and downstream signalling pathways which promote 

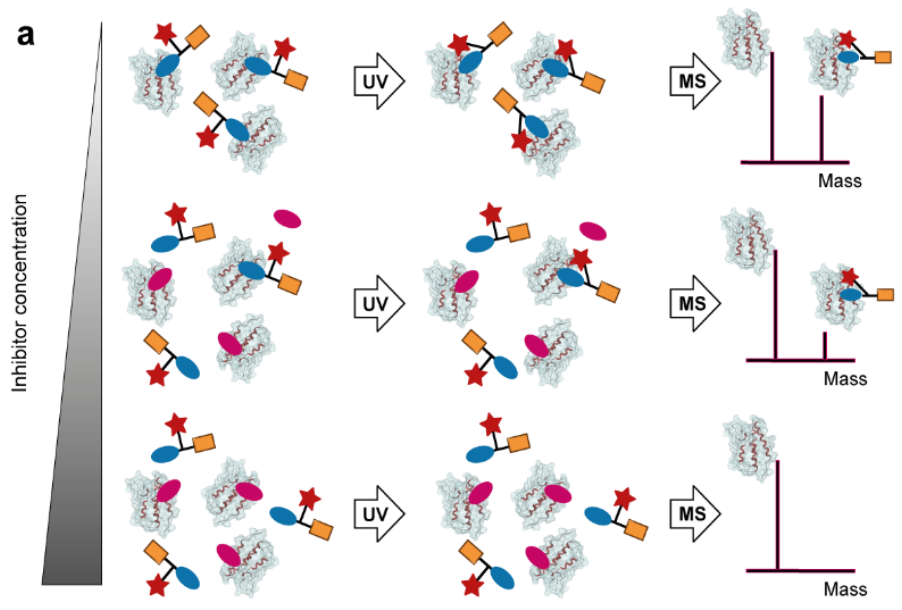

b
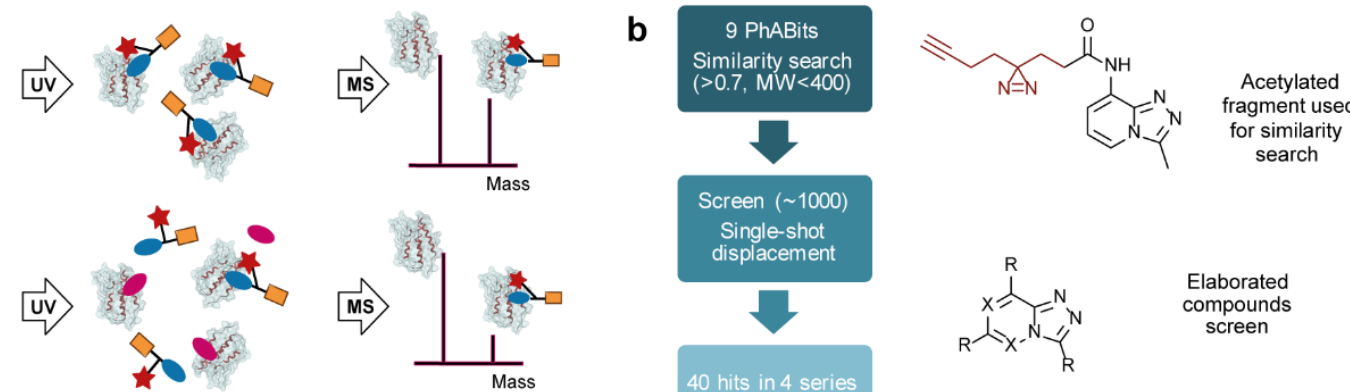

Single-shot
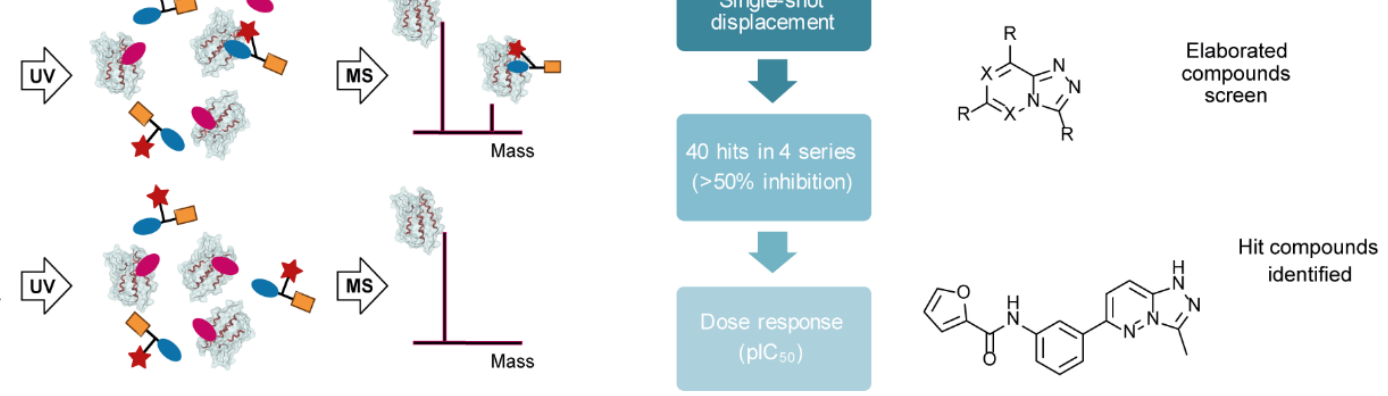

C
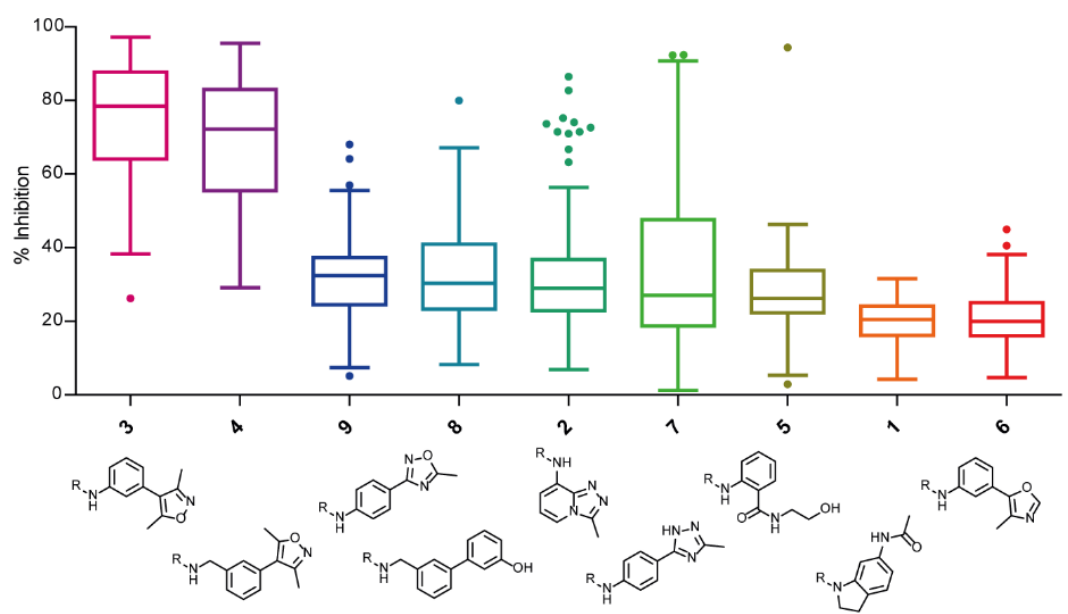

d<smiles></smiles>

22

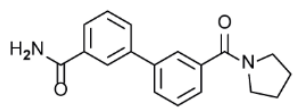

40

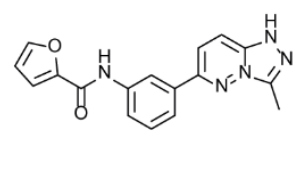

28

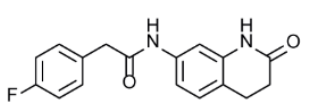

58 e

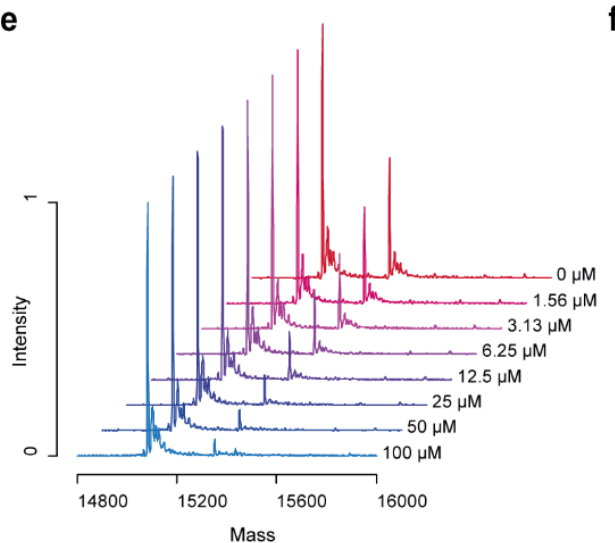

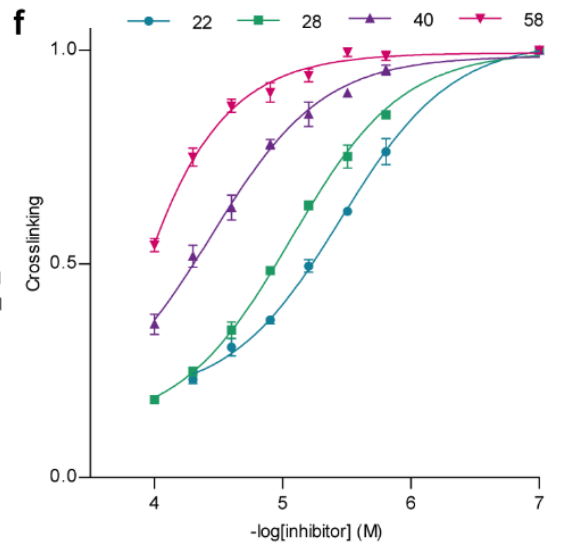

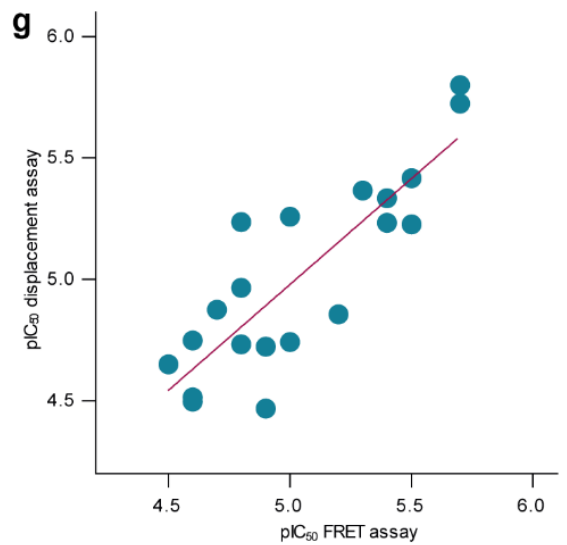

Figure 5: Photoaffinity displacement assay. A: Schematic of the displacement assay. Protein and PhABit are incubated with increasing concentrations of competitive inhibitor before UV irradiation and analysis by intact MS. B: Elaborated compounds were generated from a similarity search on nine hit PhABits (1-9). These were screened at a single concentration (100 $\mu \mathrm{M})$ to identify 40 hit compounds that showed $>50 \%$ inhibition of crosslinking of $\mathbf{2}$ to BRD4-BD1. C: Summary of the similarity search-based compound selection to identify compounds more potent than the original hit PhABits. D: Example compounds from the four chemical series that have been identified. E: Concentration-response spectra of $\mathbf{2}$ crosslinked to BRD4 in the presence of increasing concentrations of competitive inhibitor $\mathbf{2 2}$. F: Concentration-response curves generated for four compounds analysed by the displacement assay. Normalised crosslinking yield of 2+BRD4BD1 is plotted against - $\log \left[\right.$ inhibitor] $(M)$, error bars represent SEM across three replicates. $\mathbf{G}$ : Comparison of pI $\mathrm{C}_{50}$ values generated by the displacement assay $(n=3)$ versus TR-FRET assay (an additional 20 compounds showed $\mathrm{plC}_{50}$ values beyond the lower limit of the assays), line of best fit in red $\left(R^{2}=0.72\right)$.

uncontrolled cell proliferation and survival. ${ }^{54}$ The inhibition of KRas has been widely investigated for the development of oncology therapeutics, however, due to the lack of well-defined binding pockets on the protein it has proved extremely challenging to develop potent ligands. ${ }^{54-57}$ Some success has been reported using fragment screening, which enabled 
identification of micromolar, and recently submicromolar, ligands to a shallow pocket between the switch I/II regions of KRas. ${ }^{57}$ KRas fragment screening has typically employed HSQC NMR with ${ }^{15} \mathrm{~N}$-labelled protein, which is resource intensive. We explored whether the PhABit library could provide an alternative approach to identify fragment binders and their binding sites.

KRas4B ${ }^{G 12 D}$ was incubated with the PhABit library $(1 \mu \mathrm{M}, 4$ ${ }^{\circ} \mathrm{C}, 15 \mathrm{~min}, 200 \mu \mathrm{M}$ PhABit) before irradiation and analysis by LC-MS. The results were compared to the screening of BRD4BD1 and BCL6, to identify 11 unique hits for KRas, of which four were of particular interest (60-63, Figure 6A/B). These hits exemplified two chemotypes: 2-heterocyclic pyridines (60 and 61) and an indole warhead (62 and 63). The indoles are similar to previously reported KRas binders identified by NMR studies, suggesting the screen has identified true hits. ${ }^{54}$ The 2 - heterocyclic pyridines do not resemble known ligands and therefore represent novel KRas binding motifs.

The binding site of indole hit $\mathbf{6 2}$ was explored by LC-MS/MS analysis of crosslinked KRas4B ${ }^{G 12 D}$. Three modified peptides were identified corresponding to crosslinking on three different residues on the same peptide ( ${ }_{57} D T A G Q E * E^{*}{ }^{*}{ }^{*} S A M{ }^{0 x} R_{68}$, Figure $6 \mathrm{C}$ ). These residues, E62, E63 and $\mathrm{Y} 64$, lie at the loop of the switch I/II region, directly adjacent to the binding site of ligands reported previously (e.g. 64, PDB ID:4EPY, Figure 6D). ${ }^{54}$ This pocket is of functional significance in interacting with SOS1/2, the guanine nucleotide exchange factors (GEFs), which promote formation of the active KRas state. ${ }^{39}$ Thus, the PhABit platform enabled expedient identification of fragment binders to a protein of low tractability, and provided insight into the binding site of hit PhABits without the need for recourse to NMR and crystallography.

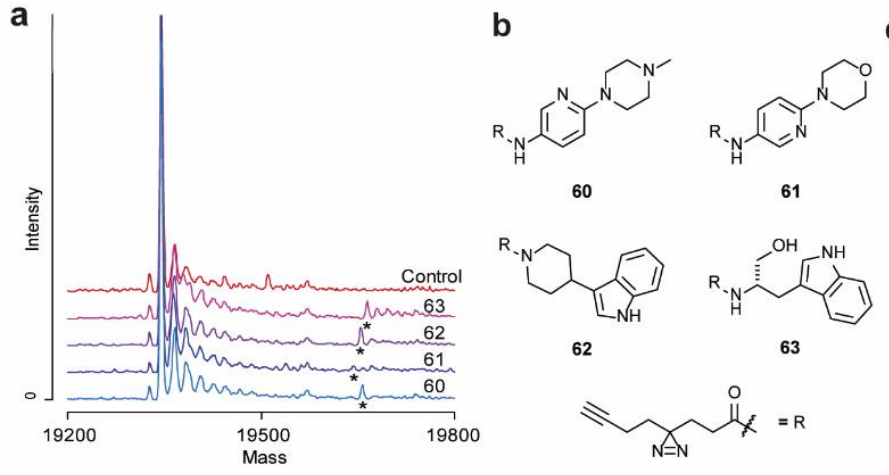

d

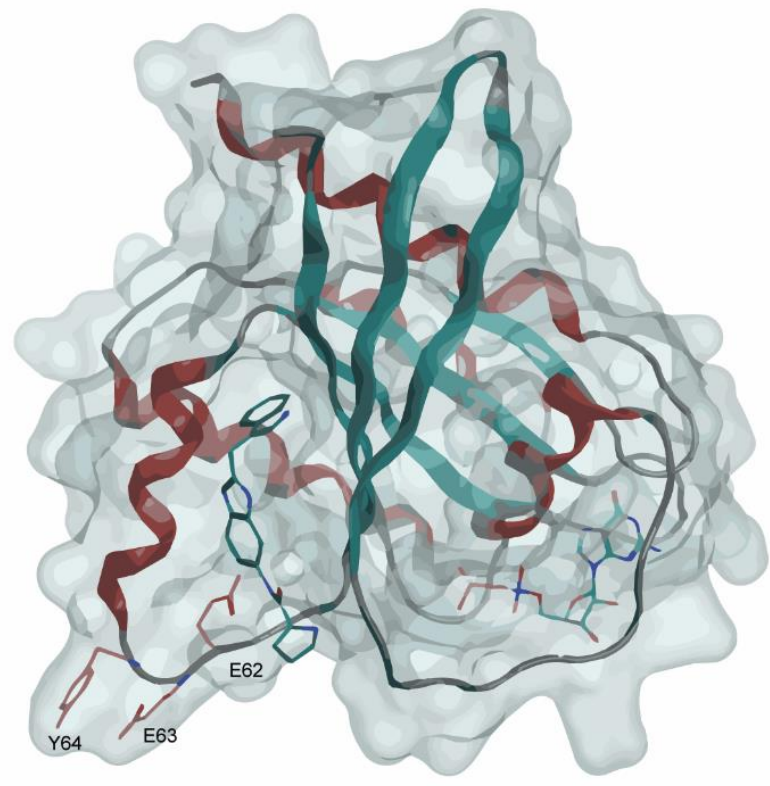

e

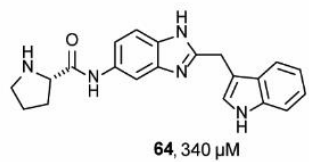

\section{(}
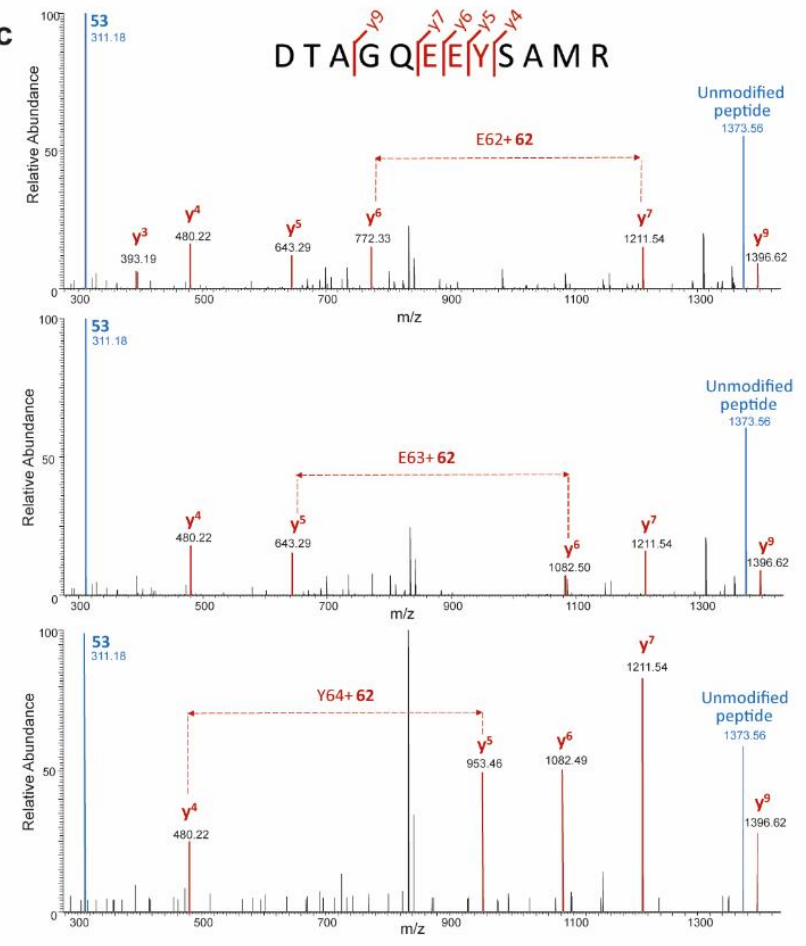

f

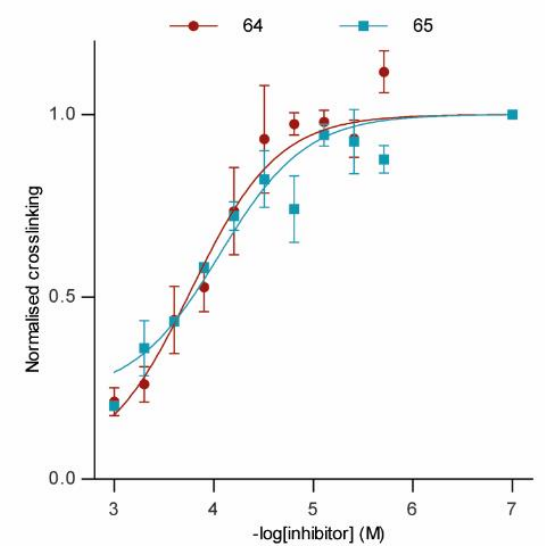

Figure 6: Application of the PhABit platform to KRas. A: Intact MS spectra of hit PhABits for KRas following irradiation with UV light. B: Structures of the four selected hit PhABits for KRas ${ }^{612 D}$. C: LC-MS/MS spectrum of the tryptic derived peptide ${ }_{58} D_{T A Q E}{ }^{*}{ }^{*} Y^{*} S A M R_{69}$ Crosslinked to 62 indicating E63, E64 and $\mathrm{Y} 65$ as the sites of crosslinking. D: Co-crystal structure of compound $\mathbf{6 4}$ bound to KRas ${ }^{\mathrm{G}} 12 \mathrm{~V}$, highlighting the amino acid residues which underwent crosslinking with 62. E: Compounds identified previously as binding to KRas ${ }^{\mathrm{G} 12 \mathrm{D}}$. F: Concentration-response curves generated for $\mathbf{6 4}$ and $\mathbf{6 5}$ analysed by displacement assay. Normalised crosslinking yield of $\mathbf{6 2 + K R a s}{ }^{\mathrm{G}} \mathbf{2 D}$ is plotted against - $\log [$ inhibitor](M), error bars represent SEM across three replicates. 
A challenge associated with KRas has been access to assays to enable efficient screening of compounds libraries. We explored the use of the photoaffinity displacement assay to measure $\mathrm{IC}_{50}$ values of compounds of interest. A range of concentrations of previously reported KRas binders 64 and 65 (Figure $6 \mathrm{E})$ were incubated with $\mathrm{KRas}^{\mathrm{B}} \mathrm{B}^{\mathrm{G12D}}(1 \mu \mathrm{M})$ and hit PhABit 62 (1 $\mathrm{mM})$ before irradiation. The crosslinking yields were determined by LC-MS to afford the expected concentration-dependent decrease in crosslinking (Figure 6F). The generated $\mathrm{IC}_{50}$ values of $170 \mu \mathrm{M}(64)$ and $90 \mu \mathrm{M}(65)$ were consistent with reported values $(64=340 \mu \mathrm{M}$, and $65=190 \mu \mathrm{M})$, which were determined by HSQC NMR using ${ }^{15} \mathrm{~N}$-labelled KRas ${ }^{\text {G12D }} .{ }^{54}$ This displacement assay therefore provides an efficient method for screening ligands against the switch I/II region binding site.

Identification of KRas fragment binders using the PhABit platform has demonstrated its utility as a screening approach for challenging protein targets. Rapid follow-up studies by LCMS/MS enabled straightforward identification of the site of binding, which was consistent with previously reported crystallographic studies. Additionally, hits provided immediate access to an assay to profile published compounds, which could prove useful for further KRas inhibitor development studies.

\section{CONCLUSIONS}

We describe a fragment screening platform (PhABits) that uses a photoreactive group (diazirine) to capture fragmentprotein binding. The approach is straightforward to implement and can be directly applied to purified proteins without the requirements of more traditional assay development. The PhABits, along with other covalent fragment approaches, offer rapid assessment of tractability and tool generation on timescales suitable for application to the large numbers of targets emerging from functional genomics analyses. In this way, the platform complements other binding assay approaches, such as ASMS and DELs, which are not typically compatible with fragments.

In addition to identifying hits, the platform enables determination of potency and site of binding, providing actionable information before optimisation of secondary assays and crystallography. Furthermore, hit PhABits can immediately be used as reporters in displacement assays to screen libraries of compounds to identify more potent binders in a site-specific manner. These tools may also prove valuable in qualifying hits from complementary approaches, such as DELs and ASMS. We have also demonstrated their utility for rapid access to PROTAC ligands.

A limitation of the approach is that proteins must first be amenable to analysis by MS. Additionally, low crosslinking yields can inhibit the detection of hits. Advances in protein mass spectrometry and development of photoreactive groups with improved crosslinking yields will improve the applicability of the approach. We anticipate the accessibility of the PhABit workflow will enable efficient identification of fragment binders to emerging biological targets. Furthermore, the informative output of the various follow-up studies will facilitate the rapid development of tool molecules for disease biology and target validation studies.

\section{ASSOCIATED CONTENT}

Biochemical methods, synthetic methods and characterisation, crystallography and supplementary figures. This material is available free of charge via the Internet at http://pubs.acs.org.

\section{AUTHOR INFORMATION}

\section{Corresponding Author \\ *jacob.x.bush@gsk.com}

\section{Notes}

The authors declare no competing financial interest.

\section{ACKNOWLEDGMENT}

We would like to thank the GlaxoSmithKline/University of Strathclyde Collaborative PhD programme for funding this work. Additionally, we would like to thank Heather Barnett, Natalie Wellaway, Daniel Tune, Pawel Slade and Alexander Vos for contributing to the synthesis of the PhABit library, Jiajun Ren for synthesis of PhABit analogues and Diana Klimaszewska for contribution to running of the HiBiT and ATP assays. We thank the EPSRC for funding via Prosperity Partnership EP/S035990/1, the SCI for funding via a 2018 Scholarship (EKG) and the Scottish Funding Council for a Postgraduate and Early Career Researcher Exchanges (PECRE) grant (H17014) (DJF).

\section{REFERENCES}

1. Tam, V.; Patel, N.; Turcotte, M.; Bossé, Y.; Paré, G.; Meyre, D., Benefits and limitations of genomewide association studies. Nat. Rev. Genet. 2019, 20, 467-484.

2. Behan, F. M.; lorio, F.; Picco, G.; Goncalves, E.; Beaver, C. M.; Migliardi, G.; Santos, R.; Rao, Y.; Sassi, F.; Pinnelli, M.; Ansari, R.; Harper, S.; Jackson, D. A.; McRae, R.; Pooley, R.; Wilkinson, P.; van der Meer, D.; Dow, D.; Buser-Doepner, C.; Bertotti, A.; Trusolino, L.; Stronach, E. A.; Saez-Rodriguez, J.; Yusa, K.; Garnett, M. J., Prioritization of cancer therapeutic targets using CRISPRCas9 screens. Nature 2019, 568 (7753), 511-516.

3. Drewes, G.; Knapp, S., Chemoproteomics and Chemical Probes for Target Discovery. Trends Biotechnol. 2018, 36 (12), 1275-1286.

4. Garbaccio, R. M.; Parmee, E. R., The impact of chemical probes in drug discovery: A pharmaceutical industry perspective. Cell Chem. Bio. 2016, 23, 10-17.

5. Antolin, A. A.; Tym, J. E.; Komianou, A.; Collins, I.; Workman, P.; Al-Lazikani, B., Objective, Quantitative, Data-Driven Assessment of Chemical Probes. Cell Chem. Bio. 2018, 25 (2), 194205.

6. Favalli, N.; Bassi, G.; Scheuermann, J.; Neri, D., DNAencoded chemical libraries - achievements and remaining challenges. FEBS Lett. 2018, 592 (12), 2168-2180.

7. Yuen, L. H.; Dana, S.; Liu, Y.; Bloom, S. I.; Thorsell, A. G.; Neri, D.; Donato, A. J.; Kireev, D.; Schuler, H.; Franzini, R. M., A Focused DNA-Encoded Chemical Library for the Discovery of Inhibitors of NAD(+)-Dependent Enzymes. J. Am. Chem. Soc. 2019, 141 (13), 5169-5181.

8. Dickson, P.; Kodadek, T., Chemical composition of DNAencoded libraries, past present and future. Org. Biomol. Chem. 2019, 17 (19), 4676-4688.

9. Goodnow, R. A., Jr.; Dumelin, C. E.; Keefe, A. D., DNAencoded chemistry: enabling the deeper sampling of chemical space. Nat. Rev. Drug Discov. 2017, 16 (2), 131-147. 
10.

Machutta, C. A.; Kollmann, C. S.; Lind, K. E.; Bai, X.; Chan, P. F.; Huang, J.; Ballell, L.; Belyanskaya, S.; Besra, G. S.; BarrosAguirre, D.; Bates, R. H.; Centrella, P. A.; Chang, S. S.; Chai, J.; Choudhry, A. E.; Coffin, A.; Davie, C. P.; Deng, H.; Deng, J.; Ding, Y.; Dodson, J. W.; Fosbenner, D. T.; Gao, E. N.; Graham, T. L.; Graybill, T. L.; Ingraham, K.; Johnson, W. P.; King, B. W.; Kwiatkowski, C. R.; Lelievre, J.; Li, Y.; Liu, X.; Lu, Q.; Lehr, R.; Mendoza-Losana, A.; Martin, J.; McCloskey, L.; McCormick, P.; O'Keefe, H. P.; O'Keeffe, T.; Pao, C.; Phelps, C. B.; Qi, H.; Rafferty, K.; Scavello, G. S.; Steiginga, M. S.; Sundersingh, F. S.; Sweitzer, S. M.; Szewczuk, L. M.; Taylor, A.; Toh, M. F.; Wang, J.; Wang, M.; Wilkins, D. J.; Xia, B.; Yao, G.; Zhang, J.; Zhou, J.; Donahue, C. P.; Messer, J. A.; Holmes, D.; Arico-Muendel, C. C.; Pope, A. J.; Gross, J. W.; Evindar, G., Prioritizing multiple therapeutic targets in parallel using automated DNA-encoded library screening. Nat. Commun. 2017, 8,16081 .

11. Kutilek, V. D.; Andrews, C. L.; Richards, M. P.; Xu, Z.; Sun, T.; Chen, Y.; Hashke, A.; Smotrov, N.; Fernandez, R.; Nickbarg, E. B.; Chamberlin, C.; Sauvagnat, B.; Curran, P. J.; Boinay, R.; Saradjian, P.; Allen, S. J.; Byrne, N.; Elsen, N. L.; Ford, R. E.; Hall, D. L.; Kornienko, M.; Rickert, K. W.; Sharma, S.; Shipman, J. M.; Lumb, K. J.; Coleman, K.; Dandliker, P. J.; Kariv, I.; Beutel, B., Integration of Affinity Selection-Mass Spectrometry and Functional Cell-Based Assays to Rapidly Triage Druggable Target Space within the NFkappaB Pathway. J. Biomol. Screen. 2016, 21 (6), 608-619.

12. Harris, P. A.; King, B. W.; Bandyopadhyay, D.; Berger, S. B.; Campobasso, N.; Capriotti, C. A.; Cox, J. A.; Dare, L.; Dong, X.; Finger, J. N.; Grady, L. C.; Hoffman, S. J.; Jeong, J. U.; Kang, J.; Kasparcova, V.; Lakdawala, A. S.; Lehr, R.; McNulty, D. E.; Nagilla, R.; Ouellette, M. T.; Pao, C. S.; Rendina, A. R.; Schaeffer, M. C.; Summerfield, J. D.; Swift, B. A.; Totoritis, R. D.; Ward, P.; Zhang, A.; Zhang, D.; Marquis, R. W.; Bertin, J.; Gough, P. J., DNA-Encoded Library Screening Identifies Benzo[b][1,4]oxazepin-4-ones as Highly Potent and Monoselective Receptor Interacting Protein 1 Kinase Inhibitors. J. Med. Chem. 2016, 59 (5), 2163-2178.

13. Deng, H.; Zhou, J.; Sundersingh, F. S.; Summerfield, J.; Somers, D.; Messer, J. A.; Satz, A. L.; Ancellin, N.; Arico-Muendel, C. C.; Sargent Bedard, K. L.; Beljean, A.; Belyanskaya, S. L.; Bingham, R.; Smith, S. E.; Boursier, E.; Carter, P.; Centrella, P. A.; Clark, M. A.; Chung, C. W.; Davie, C. P.; Delorey, J. L.; Ding, Y.; Franklin, G. J.; Grady, L. C.; Herry, K.; Hobbs, C.; Kollmann, C. S.; Morgan, B. A.; Pothier Kaushansky, L. J.; Zhou, Q., Discovery, SAR, and X-ray Binding Mode Study of BCATm Inhibitors from a Novel DNA-Encoded Library. ACS Med. Chem. Lett. 2015, 6 (8), 919-924. 14. Arico-Muendel, C.; Zhu, Z.; Dickson, H.; Parks, D.; Keicher, J.; Deng, J.; Aquilani, L.; Coppo, F.; Graybill, T.; Lind, K.; Peat, A.; Thomson, M., Encoded library technology screening of hepatitis $C$ virus NS4B yields a small-molecule compound series with in vitro replicon activity. Antimicrob. Agents Chemother. 2015, 59 (6), 3450-3459.

15. Litovchick, A.; Dumelin, C.; Habeshian, S.; Gikunju, D.; Guié, M. A.; Centrella, P.; Zhang, Y.; Sigel, E. A.; Cuozzo, J. W.; Keefe, A. D.; Clark, M. A., Encoded Library Synthesis Using Chemical Ligation and the Discovery of sEH Inhibitors from a 334Million Member Library. Sci. Rep. 2015, 5, 10916.

16. O'Connell, T. N.; Ramsay, J.; Rieth, S. F.; Shapiro, M. J.; Stroh, J. G., Solution-based indirect affinity selection mass spectrometry--a general tool for high-throughput screening of pharmaceutical compound libraries. Anal. Chem. 2014, 86 (15), 7413-7420.

17. Congreve, M.; Carr, R.; Murray, C.; Jhoti, H., A 'Rule of Three' for fragment-based lead discovery? Drug Discovery Today 2003, 8 (19), 876-877.
18. Reymond, J. L., The chemical space project. Acc. Chem. Res. 2015, 48 (3), 722-730.

19. Schuffenhauer, A.; Ruedisser, S.; Marzinzik, A.; Jahnke, W.; Selzer, P.; Jacoby, E., Library Design for Fragment Based Screening. Curr. Top. Med. Chem. 2005, 5 (8), 751-762.

20. Fisher, R.; Larkin, J., Vemurafenib: a new treatment for BRAF-V600 mutated advanced melanoma. Cancer Manag. Res. 2012, 4, 243-252.

21. Yap, J. L.; Chen, L.; Lanning, M. E.; Fletcher, S., Expanding the Cancer Arsenal with Targeted Therapies: Disarmament of the Antiapoptotic Bcl-2 Proteins by Small Molecules. J. Med. Chem. 2017, 60 (3), 821-838.

22. Markham, A., Erdafitinib: First Global Approval. Drugs 2019, 79 (9), 1017-1021.

23. Mortenson, P. N.; Erlanson, D. A.; de Esch, I. J. P.; Jahnke, W.; Johnson, C. N., Fragment-to-Lead Medicinal Chemistry Publications in 2017. J. Med. Chem. 2019, 62, 3857-3872.

24. Johnson, C. N.; Erlanson, D. A.; Jahnke, W.; Mortenson, P. N.; Rees, D. C., Fragment-to-Lead Medicinal Chemistry Publications in 2016. J. Med. Chem. 2017, 61 (5), 1774-1784.

25. Johnson, C. N.; Erlanson, D. A.; Murray, C. W.; Rees, D. C., Fragment-to-Lead Medicinal Chemistry Publications in 2015. J. Med. Chem. 2016, 60 (1), 89-99.

26. Schiebel, J.; Radeva, N.; Krimmer, S. G.; Wang, X.; Stieler, M.; Ehrmann, F. R.; Fu, K.; Metz, A.; Huschmann, F. U.; Weiss, M. S.; Mueller, U.; Heine, A.; Klebe, G., Six Biophysical Screening Methods Miss a Large Proportion of Crystallographically Discovered Fragment Hits: A Case Study. ACS Chem. Biol. 2016, 11 (6), 1693-1701.

27. Chen, I.-J.; Hubbard, R. E., Lessons for fragment library design: analysis of output from multiple screening campaigns. J. Comput. Aided Mol. Des. 2009, 23 (603-620).

28. Resnick, E.; Bradley, A.; Gan, J.; Douangamath, A.; Krojer, T.; Sethi, R.; Geurink, P. P.; Aimon, A.; Amitai, G.; Bellini, D.; Bennett, J.; Fairhead, M.; Fedorov, O.; Gabizon, R.; Gan, J.; Guo, J.; Plotnikov, A.; Reznik, N.; Ruda, G. F.; Diaz-Saez, L.; Straub, V. M.; Szommer, T.; Velupillai, S.; Zaidman, D.; Zhang, Y.; Coker, A. R.; Dowson, C. G.; Barr, H.; Wang, C.; Huber, K. V. M.; Brennan, P. E.; Ovaa, H.; von Delft, F.; London, N., Rapid covalent-probe discovery by electrophile-fragment screening. J. Am. Chem. Soc. 2019, (141), 8951-8968.

29. Craven, G. B.; Affron, D. P.; Allen, C. E.; Matthies, S.; Greener, J. G.; Morgan, R. M. L.; Tate, E. W.; Armstrong, A.; Mann, D. J., High-Throughput Kinetic Analysis for Target-Directed Covalent Ligand Discovery. Angew. Chem. Int. Ed. Engl. 2018, 57 (19), 5257-5261.

30. Bush, J. T.; Lesniak, R. K.; Yeh, T. L.; Belle, R.; Kramer, H.; Tumber, A.; Chowdhury, R.; Flashman, E.; Mecinovic, J.; Schofield, C. J., Small-molecules that covalently react with a human prolyl hydroxylase - towards activity modulation and substrate capture. Chem. Commun. (Camb) 2019, 55 (8), 1020-1023.

31. Shin, Y.; Jeong, J. W.; Wurz, R. P.; Achanta, P.; Arvedson, T.; Bartberger, M. D.; Campuzano, I. D. G.; Fucini, R.; Hansen, S. K.; Ingersoll, J.; Iwig, J. S.; Lipford, J. R.; Ma, V.; Kopecky, D. J.; McCarter, J.; San Miguel, T.; Mohr, C.; Sabet, S.; Saiki, A. Y.; Sawayama, A.; Sethofer, S.; Tegley, C. M.; Volak, L. P.; Yang, K.; Lanman, B. A.; Erlanson, D. A.; Cee, V. J., Discovery of N-(1Acryloylazetidin-3-yl)-2-(1H-indol-1-yl)acetamides as Covalent Inhibitors of KRAS(G12C). ACS Med. Chem. Lett. 2019, 10 (9), 13021308.

32. Johansson, H.; Isabella Tsai, Y. C.; Fantom, K.; Chung, C. W.; Kumper, S.; Martino, L.; Thomas, D. A.; Eberl, H. C.; Muelbaier, M.; House, D.; Rittinger, K., Fragment-Based Covalent Ligand 
Screening Enables Rapid Discovery of Inhibitors for the RBR E3 Ubiquitin Ligase HOIP. J. Am. Chem. Soc. 2019, 141 (6), 2703-2712.

33. Tuley, A.; Fast, W., The Taxonomy of Covalent Inhibitors. Biochemistry 2018, 57 (24), 3326-3337.

34. Chen, K.; Kurgan, L., Investigation of Atomic Level Patterns in Protein-Small Ligand Interactions. PLOS ONE 2009, 4 (2), e4473.

35. Bush, J. T.; Walport, L. J.; McGouran, J. F.; Leung, I. K. H.; Berridge, G.; van Berkel, S. S.; Basak, A.; Kessler, B. M.; Schofield, C. J., The Ugi four-component reaction enables expedient synthesis and comparison of photoaffinity probes. Chem. Sci. 2013, 4, 4115-4120.

36. Sherratt, A. R.; Nasheri, N.; McKay, C. S.; O’Hara, S.; Hunt, A.; Ning, Z.; Figeys, D.; Goto, N. K.; Pezacki, J. P., A New Chemical Probe for Phosphatidylinositol Kinase Activity. ChemBioChem 2014, 15, 1253-1256.

37. Desrochers, G. F.; Cornacchia, C.; McKay, C. S.; Pezacki, J. P., Activity-Based Phosphatidylinositol Kinase Probes Detect Changes to Protein-Protein Interactions During Hepatitis $C$ Virus Replication. ACS Infect. Dis. 2018, 4 (5), 752-757.

38. Parker, C. G.; Galmozzi, A.; Wang, Y.; Correia, B. E.; Sasaki, K.; Joslyn, C. M.; Kim, A. S.; Cavallaro, C. L.; Lawrence, R. M.; Johnson, S. R.; Narvaiza, I.; Saez, E.; Cravatt, B. F., Ligand and Target Discovery by Fragment-Based Screening in Human Cells. Cell 2017, 168, 527-541.

39. Kessler, D.; Gmachl, M.; Mantoulidis, A.; Martin, L. J.; Zoephel, A.; Mayer, M.; Gollner, A.; Covini, D.; Fischer, S.; Gerstberger, T.; Gmaschitz, T.; Goodwin, C.; Greb, P.; Häring, D.; Hela, W.; Hoffmann, J.; Karolyi-Oezguer, J.; Knesl, P.; Kornigg, S.; Koegl, M.; Kousek, R.; Lamarre, L.; Moser, F.; Munico-Martinez, S.; Peinsipp, C.; Phan, J.; Rinnenthal, J.; Sai, J.; Salamon, C.; Scherbantin, Y.; Schipany, K.; Schnitzer, R.; Schrenk, A.; Sharps, B.; Siszler, G.; Sun, Q.; Waterson, A.; Wolkerstorfer, B.; Zeeb, M.; Pearson, M.; Fesik, S. W.; McConnell, D. B., Drugging an undruggable pocket on KRAS. PNAS 2019, 116, 15823-15829.

40. Ziemianowicz, D. S.; Bomgarden, R.; Etienne, C.; Schriemer, D. C., Amino Acid Insertion Frequencies Arising from Photoproducts Generated Using Aliphatic Diazirines. J. Am. Soc. Mass Spectrom. 2017, 28 (10), 2011-2021.

41. Lumb, J. G.; Halloran, M. W., Recent Applications of Diazirines in Chemical Proteomics. Chem. Eur. J. 2019, 25, 48854898.

42. Mirguet, O.; Lamotte, Y.; Donche, F.; Toum, J.; Gellibert, F.; Bouillot, A.; Gosmini, R.; Nguyen, V. L.; Delannee, D.; Seal, J.; Blandel, F.; Boullay, A. B.; Boursier, E.; Martin, S.; Brusq, J. M.; Krysa, G.; Riou, A.; Tellier, R.; Costaz, A.; Huet, P.; Dudit, Y.; Trottet, L.; Kirilovsky, J.; Nicodeme, E., From ApoA1 upregulation to BET family bromodomain inhibition: discovery of I-BET151. Bioorg. Med. Chem. Lett. 2012, 22 (8), 2963-2967.

43. Balfour, J. A.; Wilde, M. I., Dorzolamide: A Review of its Pharmacology and Therapeutic Potential in the Management of Glaucoma and Ocular Hypertension. Drugs and Aging 1997, 10, 384-403.

44. Ilies, M. A.; Masereel, B.; Rolin, S.; Scozzafava, A.; Campeanu, G.; Cimpeanu, V.; T.Supuran, C., Carbonic Anhydrase inhibitors: aromatic and heterocyclic sulfonamides incorporating adamantyl moieties with strong anticonvulsant activity. Bioorg. Med. Chem. 2004, 12, 2717-2726.

45. Kassamali, R.; Sica, D. A., Acetazolamide: a forgotten diuretic agent. Cardiol. Rev. 2011, 19 (6), 276-278.

46. Filippakopoulos, P.; Qi, J.; Picaud, S.; Shen, Y.; Smith, W. B.; Fedorov, O.; Morse, E. M.; Keates, T.; Hickman, T. T.; Felletar,
I.; Philpott, M.; Munro, S.; McKeown, M. R.; Wang, Y.; Christie, A. L.; West, N.; Cameron, M. J.; Schwartz, B.; Heightman, T. D.; Thangue, N. L.; French, C. A.; Wiest, O.; Kung, A. L.; Knapp, S.; Bradner, J. E., Selective inhibition of BET bromodomains. Nature 2010, 468, 1067-1073.

47. Law, R. P.; Atkinson, S. J.; Bamborough, P.; Chung, C. W.; Demont, E. H.; Gordon, L. J.; Lindon, M.; Prinjha, R. K.; Watson, A. J. B.; Hirst, D. J., Discovery of Tetrahydroquinoxalines as Bromodomain and Extra-Terminal Domain (BET) Inhibitors with Selectivity for the Second Bromodomain. J. Med. Chem. 2018, 61 (10), 4317-4334.

48. Liu, Z.; Wang, P.; Chen, H.; Wold, E. A.; Tian, B.; Brasier, A. R.; Zhou, J., Drug Discovery Targeting Bromodomain-Containing Protein 4. J. Med. Chem. 2017, 60 (11), 4533-4558.

49. Filippakopoulos, P.; Qi, J.; Picaud, S.; Shen, Y.; Smith, W. B.; Fedorov, O.; Morse, E. M.; Keates, T.; Hickman, T. T.; Felletar, I.; Philpott, M.; Munro, S.; McKeown, M. R.; Wang, Y.; Christie, A. L.; West, N.; Cameron, M. J.; Schwartz, B.; Heightman, T. D.; La Thangue, N.; French, C. A.; Wiest, O.; Kung, A. L.; Knapp, S.; Bradner, J. E., Selective inhibition of BET bromodomains. Nature 2010, 468 (7327), 1067-73.

50. Zengerle, M.; Chan, K. H.; Ciulli, A., Selective Small Molecule Induced Degradation of the BET Bromodomain Protein BRD4. ACS Chem. Biol. 2015, 10 (8), 1770-1777.

51. Promega, Nano-Glo ${ }^{\circledR}$ HiBiT Lytic Detection System. Technical Manual, N3030.

52. Promega, CellTiter-Glo ${ }^{\circledast}$ Luminescent Cell Viability Assay. Technical Manual, G7570.

53. Grant, E. K.; Fallon, D. J.; Eberl, H. C.; G.M.Fantom, K.; Zappacosta, F.; Messenger, C.; Tomkinson, N. C. O.; Bush, J. T., A Photoaffinity Displacement Assay and Probes to Study the CyclinDependent Kinase Family. Angew. Chem. Int. Ed. Engl. 2019, 58, 17322-17327.

54. Sun, Q.; Burke, J. P.; Phan, J.; Burns, M. C.; Olejniczak, E. T.; Waterson, A. G.; Lee, T.; Rossanese, O. W.; Fesik, S. W., Discovery of small molecules that bind to K-Ras and inhibit Sosmediated activation. Angew. Chem. Int. Ed. Engl. 2012, 51 (25), 6140-6143.

55. Cruz-Migoni, A.; Canning, P.; Quevedo, C. E.; Bataille, C. J. R.; Bery, N.; Miller, A.; Russell, A. J.; Phillips, S. E. V.; Carr, S. B.; Rabbitts, T. H., Structure-based development of new RAS-effector inhibitors from a combination of active and inactive RAS-binding compounds. PNAS 2019, 116, 2545-2550.

56. Quevedo, C. E.; Cruz-Migoni, A.; Bery, N.; Miller, A.; Tanaka, T.; Petch, D.; Bataille, C. J. R.; Lee, L. Y. W.; Fallon, P. S.; Tulmin, H.; Ehebauer, M. T.; Fernandez-Fuentes, N.; Russell, A. J.; Carr, S. B.; Phillips, S. E. V.; Rabbitts, T. H., Small molecule inhibitors of RAS-effector protein interactions derived using an intracellular antibody fragment. Nat. Commun. 2018, 9 (1), 31693180 .

57. Maurer, T.; Garrenton, L. S.; Oh, A.; Pitts, K.; Anderson, D. J.; Skelton, N. J.; Fauber, B. P.; Pan, B.; Malek, S.; Stokoe, D.; Ludlam, M. J.; Bowman, K. K.; Wu, J.; Giannetti, A. M.; Starovasnik, M. A.; Mellman, I.; Jackson, P. K.; Rudolph, J.; Wang, W.; Fang, G., Small-molecule ligands bind to a distinct pocket in Ras and inhibit SOS-mediated nucleotide exchange activity. PNAS 2012, 109 (14), 5299-5304. 
